\title{
EL OCCIDENTE ISLÁMICO EN LA OBRA DE AL-MUQADDASĪ
}

\author{
The Islamic West in the Work of al-Mukaddasi
}

\author{
Claudia Patarnello \\ claudia.patarnello@libero.it \\ Universidad de Salamanca. España
}

Fecha de recepción: 31/03/2020

Fecha de aceptación: 05/06/2020

RESUMEN: En el presente artículo se hará una aproximación a la obra geográfica de al-Muqaddasī (380/990), Kitāb ahsan al-taqāsīm fi ma'rifat al-aqālīm (La mejor división para el conocimiento de las provincias). Su concepción geográfica y su metodología sistemática lo convierten en uno de los mejores representantes de la literatura geográfica del siglo $X$. Aunque su obra abarca la geografía del imperio controlado por los musulmanes (mamlaka), el trabajo se centrará exclusivamente en Occidente islámico, del que al-Muqaddasī ofrece una visión muy interesante, tanto por su origen oriental como por las fuentes utilizadas (no viajó a al-Andalus y es poco probable que lo hiciera al Mágreb, lo cual no resta objetividad a su trabajo). Como cultivador del género de al-masālik wa-lmamālik (Los caminos y los reinos), se ocupó de los topónimos y rutas principales occidentales, los cuales detalla exhaustivamente en su obra. Pero su labor de especialista fue más allá, interesándose por aspectos propios de la geografía física y humana. Por esta razón, en su obra ofrece muchos detalles sobre las poblaciones de las zonas descritas (costumbres, tipos de comida, vestimenta, religión etc...), aportando un testimonio único y preciso de gran valor para todos los interesados el Occidente islámico medieval.

PALABRAS CLAVE: al-Muqaddasī; al-masālik wa-l-mamālik; geografía humana; Occidente islámico; toponimia.

ABSTRACT: In this article we are going to approach the geographical work of al-Muḳaddasi (380/990), Kitāb ahsan al-taqāsīm fi ma'rifat al-aqālīm (The best divisions for knowledge of the regions). His geographical conception and his systematic methodology make him one of the best representative figures of the geographical literature of the $10^{\text {th }}$ century. Even though, his work includes the geography of empire controlled by Muslims (mamlaka), my contribution just will focus on the Western Islamic world, of which al-Muḳaddasī offers an interesting point of view, firstly for his oriental 
origin, and secondly for the sources used (he didn't travel to al-Ándalus, and there are few possibilities that he did it to the Maghreb, but that doesn't diminish his work). As an intellectual of the genre almasālik wa-l-mamālik (the paths and kingdoms), he focused on toponymies and principle western routes, which are exhaustively detailed in his work. However, his work as an expert went beyond a part of the physical geographic, so that he focused his interest also in aspects typical of the human geographic. For that reason, his work offers a lot of details about populations of the areas described (habits, food, clothes, religion etc.), providing a testimony which is unique and precise, with a huge value for who is interested in Western Islamic medieval world.

KEYWORDS: al-Muḳaddasī; al-masālik wa-I-mamālik; human geography; Western Islamic world; toponymy.

SUMARIO: 1. Introducción: al-Muqaddasī y su obra geográfica. 2. 2.La configuración del espacio magrebí: territorios y divisions. 3. La geografía del occidente islámico: rutas y paisaje. 4. Los habitants. 5. Producción agrícola, medidas y monedas. 6 . El islam magrebí: usos materiales y tradición doctrinal. 7. A modo de conclusion. 8. Referencias bibliográficas.

\section{INTRODUCCIÓN: AL-MUQADDASĪ Y SU OBRA GEOGRÁFICA ${ }^{1}$}

Ante la nueva situación geopolítica de los siglos Ix y X, los funcionarios, visires y califas, debido a sus intereses político-militares, prestaron especial importancia a las obras de carácter geográfico. Fue en este escenario donde se situó el germen del género al-masālik wa al-mamālik (los caminos y los reinos)². Al-Muqaddasī, junto con su contemporáneo Ibn Hawqal, es el mayor representante de este género y en cierta medida un renovador del mismo (Franco-Sánchez, 2006, p. 49). Por ello resulta de particular interés el estudio de su obra, el Ahsan al-taqāsim fi márifat al-aqālim (La mejor división para el conocimiento de las provincias). Este será el objetivo del presente trabajo: analizar la imagen que este geógrafo oriental ofrece del Occidente islámico, conforme a su concepción administrativa del imperio controlado por los musulmanes, y abordar la información cuidadosamente organizada que transmite sobre el mismo y que posee en sí misma un valor específico para los interesados en el Mágreb medieval.

No se hallan muchos datos biográficos del geógrafo en cuestión; lo poco que se conoce es gracias a su propia obra, donde él mismo menciona unas fechas e información que nos permiten hacer una aproximación sobre quién era al-Muqaddasī y cuáles fueron los momentos más destacados de su vida. Nació en Palestina, en Bayt al-Muqaddas, lugar de donde recibe la nisba (o gentilicio), alrededor del año 334/945 y falleció en torno al año 380/990. Al-Muqaddasī vivió en un entorno familiar que le permitió recibir una buena educación en distintas disciplinas:

${ }^{1}$ El sistema de transcripción del alfabeto árabe en caractres latinos que he seguido en estas páginas, difiere ligeramente del empleado por la escuela de arabistas españoles: ' $b \mathrm{t} t \mathrm{~g}$ g $h \mathrm{~h} \mathrm{~b} d \underline{d}$ r z šs ș ḍ z z 'g f q k I m n h w y āīù à aw ay.

2 Véase Franco Sánchez, 2017. 
literatura, fiqh, las escuelas jurídicas, y gramática, entre otras (Miquel, 1993, pp. 492b-493a). El Ahsan al-taqāsim es la única obra que se le conoce y a la cual dedicó muchos años de su vida. Ya desde el prefacio al-Muqaddasĩ deja claros los objetivos que quiere alcanzar con su labor de geógrafo, que son, por un lado, proporcionar "la mejor división administrativa del mundo» y, por otro, completar la información que ofrecieron sus predecesores. Asimismo, expresa la voluntad de concebir una nueva ciencia, que él define como "verdadera geografía», la cual no se ocuparía únicamente de los elementos físicos del terriorio, sino también de los humanos, los relacionados con los individuos y grupos de cada zona descrita (Miquel, 1993, p. 493a). Los objetivos que se propone alcanzar posiblemente tengan un transfondo político, e incluso religioso; de hecho, según el estudio de André Miquel, al-Muqaddasī tiene una función casi de misionero que le lleva a anotar cualquier detalle acerca de las distintas creencias y ramas pertenecientes al islam y sus implicaciones políticas (2001, p. 283).

Por otra parte, su obra se inscribe, así como otras de su época, en el género al-Masālik wa al-Mamālik, mediante el que los geógrafos árabes tenían como objetivo realizar una tabla territorial de la dār al-islām o mamlaka (la casa o el dominio del islam) que fuera coherente frente al mundo de los infieles y, a la vez, destacar la implantación del modelo cultural arabo-islámico en los territorios musulmanes (Miquel, 1963). En su obra se pueden detectar influencias de la tradición pasada, pero, con toda probabilidad, se puede afirmar que pertenece a la escuela de Balhī, creada por Abū Zayd Aḥmad b. Sahl al-Balhī (Franco-Sánchez, 2006, p. 49). Dicha escuela se caracteriza por sus cartografías donde se señalaban las fronteras de todas las provincias, islámicas o no, con la finalidad de ofrecer un cuadro étnico y político del mundo que fuera lo más objetivo y realista posible. Ahora bien, al-Muqaddasī aporta una serie de innovaciones a la propia escuela que hacen que su obra sea original. En el Ahsan al-taqāsim se aprecia la preocupación constante del autor por utilizar una metodología clara y rigurosa, que ha hecho que el trabajo de selección de datos para estas páginas resultara, en cierta medida, más sencillo.

Además de lo expuesto, conviene destacar la nueva concepción que alMuqaddasī ofrece del Occidente islámico: si hasta ese momento se había considerado que solo el Mágreb y al-Ándalus integraban ese espacio, él englobaría también la isla de Sicilia. Esta nueva percepción territorial constituyó una novedad en el discurso científico de la época, ya que Sicilia siempre se había considerado parte de la dār al-islām, pero como territorio aislado por su naturaleza geográfica. Asímismo, el Aḥsan al-taqāsim es un texto revelador porque da una visión particular, la de un geógrafo oriental sobre los territorios del Occidente islámico. Aún teniendo un fuerte vínculo con sus orígenes, el Šām (la región de Siria-Palestina)-que de hecho ocupa un espacio mayor en su obra-, la distribución espacial y los detalles que ofrece sobre el Occidente son valiosos no únicamente por su contenido, sino también porque son fruto de una rigurosa sistematización. 
No está documentado con seguridad que al-Muqaddasī conociera por sí mismo el Mágreb, y no se puede, por tanto, descartar que haya realizado algún viaje de forma puntual. Sin embargo, sí se sabe con total seguridad que nunca llegó a entrar en al-Ándalus, ya que él mismo informa de ello: «Y aunque no hemos llegado a entrar en al-Ándalus, podemos establecer su división territorial» (al-Muqaddasī, 1906, p. 216). Con todo, la falta de confirmación sobre un ocasional viaje al Occidente islámico no implica en ningún caso que la información que transmite sea ficticia o de escasa fiabilidad. Él mismo confirma que tuvo muchos informantes andalusíes (al-Muqaddasī, 1906, p. 235 y García San Juan, pp. 48-50) y es lógico que recabara datos entre sabios magrebíes, o entre ulemas orientales que hubieran visitado el Occidente islámico. De todas formas, no constituye un caso único, pues hubo otros geógrafos que no visitaron las zonas que describen. Dos ejemplos muy significativos de ello son al-Bakrī (s. XI), que nunca salió de al-Ándalus, pero que se ocupó exhaustivamente del norte de África, además de realizar un diccionario de toponimia de la Península Arábiga; y Yaqūt al-Rūmī (s. XIII) que solo pudo viajar por Oriente, a pesar de lo cual incluyó en su Mu'ğam al-Buldān (Diccionario de los países) no pocas entradas dedicadas al Mágreb y al-Ándalus.

En este sentido, se puede afirmar que su libro se basa mayoritariamente en testimonios orales; es decir, que sus informantes han sido su fuente primaria para la recopilación de datos. Ahora bien, al-Muqaddasī era un hombre letrado y, por ello, conoció las obras de geógrafos anteriores que fueron, al mismo tiempo, objeto de estudio y crítica por su parte. Él mismo afirma su voluntad de utilizar un método distinto al de sus predecesores: se niega a repetir información mencionada por otros autores, criticando de forma evidente a los que copiaban de obras anteriores, porque era una práctica que le resultaba desagradable. Sin duda este planteamiento constuía una ruptura importante en la tradición cultural araboislámica, metodológicamente articulada sobre el binomio de 'aql (razón)-naql (transmisión, y por ende, repetición):

Entre las excelencias de nuestro libro está la de evitar lo que ya han mencionado otros, pues ese rasgo más desagradable de sus obras es lo opuesto a lo que hemos hecho. ¿No te das cuenta que si miras el libro de al-Ǧayhānī, verás que comprende todos los contenidos del trabajo original de Hurradādbih? Pues lo ha construido así. Y si echas un vistazo al libro de Ibn al-Faqīh, es como si estuvieras leyendo la obra de al-Ǧāḥiz y al-Zìğ al-A'żam (Gran Tabla Astronómica). Sin embargo, si lees nuestro libro puedes notar que habla por sí mismo, y a pesar de ser como un huérfano, su organización es única (al-Muqaddasī, 1906, p. 241)3.

${ }^{3}$ He seguido en todo el trabajo la edición de De Goeje en la Bibliotheca Geographorum Arabicorum, como figura en la bibliografía final. Existe una edición y traducción parcial francesa a cargo de Pellat, Ch. (1950), que he tenido en cuenta y cito asimismo en la bibliografía. No obstante, todos los fragmentos traducidos al español son míos y realizados desde el texto árabe de De Goeje. 
Ante estas premisas, solo cabe buscar la originalidad del Ahsan al-taqāsim en una nueva concepción que se apoyará en la terminología y en la sistematización de los datos, sobre los que volveré enseguida. Mediante ellos, no solo establecerá una exacta clasificación territorial de todo el del imperio islámico, y por extensión, de su región occidental, sino que también fijará con mayor precisión los temas de estudio del especialista consagrado a la geografía humana. Ello redunda en su objetividad, precisión y veracidad que son los valores que le reconoce la historiografía moderna (Miquel, 1963, p. xxxiii).

\section{LA CONFIGURACIÓN DEL ESPACIO MAGREBÍ: TERRITORIOS Y DIVISIONES}

Es evidente que al-Muqaddasī, siendo geógrafo y cultivando el género almasālik wa al-mamālik, dio especial importancia a las rutas y a las distancias entre una ciudad a otra, midiendo los recorridos por jornadas (marhala) de viaje. Pero antes de abordar dichos trayectos, es importante conceder espacio a su terminología, técnica y precisa, para referirse a cada unidad territorial administrativa. A continuación daré algunos ejemplos para el espacio del Mágreb, pero, como es obvio, él la aplica a todo el espacio araboislámico.

Al-Muqaddasī hace uso del término iqlīm por la herencia griega recibida por todos los geógrafos (Tixier du Mesnil, 2014, pp. 21-22). Lo emplea para referirse al Occidente islámico (Mágreb, al-Ándalus y Sicilia), designando la provincia o territorio administrado por una misma autoridad política y cuya población posee unas carácterísticas propias que la identifican bien (Miquel, 2001, pp. 281-282).

También se vale de la voz mișr para referirse a la ciudad principal, es decir, el centro de cada provincia, la capital donde reside el gobierno y sus órganos administrativos, que, en el caso de esta región occidental es doble: Córdoba y alQayrawān. Ello matiza el significado original del término tradicionalmente ligado a las primeras conquistas del islam en las que se establecieron ciudades-campamento o ciudades acuarteladas, como fue, por ejemplo, el caso de Kūfa, Bașra o al-Fusțāț (Bosworth, 1993, p. 146b). Aparte de la capital, al-Muqaddasī menciona otras ciudades relevantes -madīna, o en plural, mudun-pero que dependen de la capital (miṣr). Tratándose del Mágreb cita los ejemplos de Dā̄t al-Ḥumām, Marsà al-H̆araz, Sūq Ḥamza, al-Qusțanțīniyya, al-Masīla, Sațīf, Ǧayyān, o Catania, entre otras muchas.

Todos estos enclaves se ubican en un distrito o cora (kūra), concepto administrativo que al-Muqaddasī considera una aportación propia. Aunque a menudo emplea también el término rustāq que podría traducirse asimismo por distrito o cantón, existe una diferencia apreciable entre ambos. La cora es una entidad territorial mayor en la que podrían emplazarse otras unidades administrativas menores compuestas por los rustāq-s. Como coras del Occidente islámico, al-Muqaddasī 
menciona, entre otras, Barqa, Fās, Tāzrart, Sūs, Bağğāna, Māliqa, Balansiya, Tudmīr, Saraqūsa, Yābisa. En cambio, entre los distritos menores o cantones, incluye, por ejemplo, a Qamūda, Makna Abī Manșūr, Qabiša, Rușfa, balad al-Ġumār, 'Arīš, Šantarīn, Tabassā, Ūliya (Miquel, 2001, pp. 281-282).

En cualquier caso, estos dos últimos términos administrativos son de especial importancia en su discurso geográfico del que se puede deducir que los distritos rurales constituyen de algún modo la fuerza motriz permite el buen funcionamiento de las grandes ciudades. En palabras del propio autor:

Deberías saber que un distrito ( $k u \bar{r} a)$ no es célebre por su número de ciudades, sino por la grandeza de sus cantones (rasātīq) ¿Es que no ves la importancia de Nisābūr y Buhāāā, a pesar del escaso número de ciudades (mudun) y, en cambio, el lamentable estado de pobreza de Zabīd y Hağar pese a tener muchas ciudades (mudun)? (alMuqaddasī, 1906, p. 228).

Para finalizar hay que añadir que al-Muqaddasī emplea la voz nāḥiya en sentido amplio, eso es, región o zona, para designar, por ejemplo el Zāb, Tánger y Ġāfiq.

\section{LA GEOGRAFÍA DEL OCCIDENTE ISLÁMICO: RUTAS Y PAISAJE}

Un aspecto importante en la configuracíón del territorio son las rutas e itinerarios que constituyeron la esencia del género geográfico en sus orígenes. Al hablar del Mágreb y al-Andalus, como no podía ser de otro modo, al-Muqaddasī les dedicó mucha atención. Por lo general se trata de fragmentos breves y muy directos en los que, como se ha dicho, la distancia se mide en jornadas o días que toman como referencia los enclaves más próximos. Señalo a continuación dos de los innumerables ejemplos que podrían mencionarse:

Desde al-Qayrawān, para llegar a Qafșa, se tardan siete jornadas de viaje y de aquí hasta Qasțîliya son tres días de viaje; de aquí, para llegar a Tāhart, se tardan quince días, pasando por áreas de arena y algunos pueblos. Después hay que viajar durante tres días en territorio bereber para llegar a Fās [...] Desde Maǧğāna para ir a Tabassa, Bāgāày, Dūfāna, 'Ayn al-'Așāfirr, Dār Maluwwal, Ṭubna, Maqqara y al-Masīla siempre se tarda una jornada de viaje; entre cada una de ellas y la ciudad sucesiva, siguiendo el orden dado, hay una jornada de viaje. (al-Muqaddasī, 1906, p. 246).

En ambos fragmentos se aprecia la concisión y concreción de los datos orientadas al contenido primordial, los caminos y distancias entre los lugares de referencia, con una ligerísima indicación geográfica de lo que haya entre ellos. El discurso es muy repetitivo, hasta el punto de que en numerosas páginas las obras de al-masālik 
wa-l-mamālik -también la de al-Muqaddasī- se convierten en un mero nomenclátor de enclaves y distancias (Manzano, 2017, pp. 146-147).

Con todo, las rutas no son la única preocupación para al-Muqaddasī, quien se interesó enormememente por otros aspectos de las zonas descritas. Uno de ellos es el paisajístico en todas sus facetas: la naturaleza o el aspecto arquitectónico de las ciudades entre otros. Para él, el Occidente islámico es una provincia con una gran diversidad geográfica -costa, montañas, llanuras, desiertos, etc.- que, además, destaca por su fertilidad y sus recursos naturales, cuyo acceso también constituye objeto de interés, como se comprobará en las siguientes líneas:

Esta es una provincia hermosa, extensa y particular. Posee muchas ciudades (mudun) y pueblos (qurà), así como unas características y una prosperidad extraordinarias. En esta provincia se encuentran importantes ciudades fronterizas, muchas fortalezas y agradables jardines [...] Sus ciudades se ocultan entre [la multitud de] olivos. En su tierra, cubierta de higos y viñedos, se abren paso varios ríos, y los campos están repletos de árboles. Con todo, está alejadísimo, posee muchas zonas desérticas (mafāwiz), con caminos difíciles y muy peligrosos (al-Muqaddasī, 1906, pp. 215-216).

En este proceso de descripción del paisaje, al-Muqaddasī sistematiza asimismo la información relacionada con las ciudades: proximidad o lejanía del desierto y las montañas, recursos hídricos, cultivos agrícolas, fortificaciones, y distribución urbana en barrios o edificios de interés si se trata las capitales. Es un patrón claramente establecido y reiterativo:

Ağdābiyya está poblada ('āmira) y está construida en piedra al lado del mar. Sus recursos de agua provienen de la lluvia. A Surt le pasa lo mismo, y las dos tienen zonas desérticas (bawād/badāwa) y de arbustos. Șabra está en el desierto (bādiya), es una ciudad fortificada (ḥașina) y tiene palmeras e higos [...] Mittiğa está en una pradera en la que hay un curso de agua sobre el que han dispuesto molinos; una parte del río se introduce en las casas; tiene muchos huertos [...] Córdoba es la capital (mișr) de al-Ándalus; escuché a un 'Uțmānī decir que esta ciudad era más importante que Bagdad. Se sitúa en una llanura desértica (șahrā') dominada por una montaña. Se compone de una ciudad en el interior (al-madina) y de arrabales (al-rabaḍ). La gran mezquita se halla en al-madīna, [centro de la ciudad], así como [algunos] zocos; sin embargo, la mayoría de ellos y la sede del gobernante (dār al-sulțān) están en las afueras. Enfrente de la ciudad fluye un grande río. Los techos están hechos de azulejos. [En cambio], la mezquita es de piedra y argamasa con columnas de mármol y está rodeada de lavabos para las abluciones. La ciudad tiene cinco puertas: Bāb al-Ḥadīd, Bāb al-'Ațțārīn, Bāb al-Qanțara, Bāb al-Yahūd y Bāb 'Āmir. (al-Muqaddasī, 1906 , pp. 224, 228 y 233). 


\section{LOS HABITANTES}

Al-Muqaddasī dedica asimismo un espacio relevante a los habitantes del Occidente islámico, de los que tiene, en líneas generales, una buena opinitón. Grosso modo, transmite al lector la impresión de que es una población amable, comprometida con la religión, en búsqueda de conocimiento y muy trabajadora, especialmente en el ámbito comercial. Además, afirma que tanto magrebíes como andalusíes son gente que está en continuo ğihād, afirmación esta que podría estar haciendo referencia a las conocidas tradiciones sobre el Magreb que circulaban en esta época (de Felipe, 2018, p. 95). Los textos son muy claros a este respecto:

El Mágreb está conectado a su mejor vecino, el mar, y sus habitantes son benévolos para aquellos viajeros que atraviesan la provincia [...] La gente es amable, le gusta el conocimiento y está muy ocupada con el comercio y moviéndose de un sitio para otro [...] La región (nāhiya) de al-Ándalus se parece por completo en su naturaleza a Hayțal. Los habitantes están en continuo ğihād; a sus cualidades se añaden una ciencia profunda, un gobernante poderoso, algunas especialidades, una intensa actividad comercial y unos beneficios de gran consideración (al-Muqaddasī, 1906, p. 233).

Y si particulariza en en algunas ciudades, la opinión es igualmente favorable, como en este fragmento referido a Barqa:

Barqa se extiende sobre el camino principal que va hacia Egipto y [sus habitantes] se comportan bien hacia los extranjeros y son gente de bien y rectitud; además, se sublevan menos que otros [...] No verás [un lugar] con tantas ciudades y con gente más bondadosa. Entre su gente solo hay hanafíes y malikíes que viven en armonía y entre ellos no siembran discordia ni sectarismo. No hay duda de que están iluminados por la luz de Dios ya que aceptan las fatigas sin fomentar la sed de venganza en sus corazones. (al-Muqaddasī, 1906, pp. 224-225).

Con todo, esta visión general sobre magrebíes y andalusíes, es muy matizable al hablar específicamente sobre los bereberes. Según él, este grupo humano, que habita principalmente las zonas rurales de la región, son gente agresiva, sin modales, mezquina, incapaces de hablar o de hacerse entender, ya que, cuando hablan no se les entiende nada, al tener un idioma incomprensible. Cabe señalar que esta visión tan despectiva y negativa que nos da al-Muqaddasī sobre los bereberes, va a estar relativamente generalizada en las fuentes árabes, tanto de su época como de períodos posteriores. Esta pésima percepción sobre los bereberes se podría explicar con el hecho de que no estuvieran todavía del todo islamizados: 
En la mayor parte de las zonas rurales de esta provincia (iqlimm) habitan los Bereberes, aunque la mayoría se concentran en el distrito (kūra) de Sūs. Son un pueblo (qawm) del mismo tipo que la gente al-Hawārizm: su lengua es incomprensible, su naturaleza es desagradable porque son mezquinos y violentos [...] A lo dicho, hay que añadir que son groseros, de mal carácter y rudos (al-Muqaddasī, 1906, p. 243).

Como es sabido, la comida es parte integrante de la cultura de una población. También al-Muqaddasī da información sobre ella, haciendo referencia incluso a platos específicos, como por ejemplo la turda, que es una especie de sopa que se comía con trocitos de pan y carne (Lane, 1984, p. 334c) o a deteminados usos culinarios no muy aceptables, como la preparación de carne de perro con al-harā i is ${ }^{4}$ (al-Muqaddasī, 1906, p. 243).

\section{PRODUCCIÓN AGRÍCOLA, MEDIDAS Y MONEDAS}

Al-Muqaddasi traslada una imagen del Occidente islámico como una tierra fértil que garantizaba, gracias a sus recursos naturales, el abastecimiento de la región. Entre los cultivos mencionados más frecuentemente se hallan: aceitunas, higos, trigo, azafrán, uva, dátiles, pasas, pistachos, albaricoque, almendras, granadas, miel, manzanas y muchos más productos agrícolas. También en esta ocasión, el autor es coherente con su metodología precisa y detallista, en el sentido de que especifica la procedencia de cada producto, presentando una auténtica cartografía de la producción agrícola:

Trípoli [...] tiene muchos frutos: [como por ejemplo] peras, manzanas, además de productos lácteos y miel [...] Barqa constituye una ciudad importante (qașaba), floreciente y valiosa. Abundan los frutos, diversos tipos de trigo (al-jayrāt) y varios tipos de miel, por eso la vida es próspera [...] Tiene Siğilmāsa una gran provisión de dátiles, uvas, pasas, fruta, trigo (hubūb), granadas y otros tipos de productos agrícolas (jayrāt) [...] Ğayyān (Jaén) consta de numerosas regiones (nawāḥi) cuyas ciudades principales son (mudun): al-Ǧafr, en montaña, a 10 millas de Ǧayyān; esta localidad, que posee un gran número de ríos y molinos, está cubierta de vegetación y produce aceitunas, uvas y todo tipo de frutos. Bayġū (Priego) está en la montaña; de los ríos manan fuentes, que pasan por los molinos y los activan. Tiene muchas moreras, olivos e higueras. Mārtuš (Martos) es una ciudad amurallada que se sitúa en montaña; el agua que beben es de pozos y hay un gran número de higueras, olivos y viñedos. (al-Muqaddasī, 1906, pp. $224,231,234-235)$.

${ }^{4}$ Se trata del plural de harīsa, que es una salsa picante que se utiliza, especialmente en Túnez, como condimento. Véase Bardenstein, 2002, en concreto, p. 376, nota 16; Dozy, 1927, p. 754. 
Interesado en el comercio no podía faltar en su obra un apartado dedicado a los pesos y medidas, así como a las monedas utilizadas. Al-Muqaddasī informa de que en toda la región se usa el arrelde (arțal), medida de capacidad empleada en Bagdad, que se mantuvo mientras los abbasíes mantuvieron su dominio en la zona. Con la llegada de los fatimíes se introdujo un arrelde más pesado. Sin embargo, en al-Ándalus se utilizaba un arrelde que tenía otro peso, dependiendo de su uso: el empleado para pesar la carne era cuatro veces más pesado que el utilizado en el Mágreb (Ashtor, 1991, pp. 117b-120b). Con el cahíz (qafiz), medida de capacidad mayor, hubo asimismo variaciones en al-Ándalus y el Mágreb (Asthor, 1991, p. 121a; Cardarelli, 2003, p. 78). Todas ellas las detalla asimismo al-Muqaddasī, junto con otras unidades empleadas. Entre las monedas, menciona el uso del dinar y el dirham y otras unidades inferiores, si bien considero muy prolijo detenerme en todas ellas (al-Muqaddasī, 1906, p. 240).

\section{EL ISLAM MAGREBÍ: USOS MATERIALES Y TRADICIÓN DOCTRINAL}

Aunque breve, otro apartado interesante del Ahsan al-taqāsim es el dedicado a la vestimenta y los tejidos típicos de la región occidental. De manera esporádica, se utilizaba el țaylasān, es un tipo de prenda exterior y drapeada, que podría ser una variedad del tipo kisā' (Serrano-Niza, 2005, pp. 47 y 149) o se describe también como un pañuelo ligero que se pone sobre la cabeza y los hombros (Dozy, 1845, p. 278) y al parecer era una moda más bien egipcia que muy pocos magrebíes seguían (al-Muqaddasī, 1906, p. 239). Las personas que usaban bonetes (qalānisa) los llevaban teñidos de distintos colores, mientras que los bereberes usaban el albornoz negro (burnus). Los habitantes de los cantones (rasātiq) se ponían vestidos hechos a medida, mientras que el vulgo usaba unos pañuelos ligeros (manādīl) (alMuqaddasī, 1906, p. 239). En relación con los tejidos, se afirma que de Barqa se exportaban telas de lana y que un molusco -llamado Abū Qalamūn- era muy apreciado porque se utilizaba para producir ropa brillante y de diversos colores (Huisman, 1986, pp. 131a-131b). Sin embargo, la información es muy lacónica sobre Sicilia - «tenía los mejores vestidos cortos»-e inexistente sobre al-Ándalus del que no da información (al-Muqaddasī, 1906, p. 239).

Por último, en esta visión del Occidente islámico ofrecida por al-Muqaddasī, cabe señalar su especial interés por la distribución de las distintas escuelas jurídicas en este territorio. Según él, solo eran aceptadas dos escuelas: la mālikí y la ḥanafí, rechazando abiertamente la šāfi í. La primera se extiendía tanto en al-Ándalus, como en el Mágreb, mientras que la segunda era profesada mayoritariamente en Sicilia y en menor medida en los otros territorios occidentales. En todos ellos se seguían las lecturas coránicas de Nāfi' (m. 169/785), y ambas escuelas jurídicas convivían de manera armónica, alternando en algún caso gobernadores políticos 
de una y otra cada año. Los únicos grupos totalmente inaceptables en estos lugares eran los ši íes y mu'tazilíes hasta el punto de que se arriesgaban a perder su vida si se adentraban en ellos (al-Muqaddasī, 1906, pp. 236-237).

En este sentido, resulta llamativo el conocimiento que demuestra al-Muqaddasī sobre la doctrina fatimí y sus divisiones (al-Muqaddasī, 1906, p. 237). Para los especialistas, ello constituye una prueba de sus tendencias en pro de esta dinastía y su califato, en cuya propaganda estaría muy implicado, aunque igualmente alejado de fanatismos o extremismos. Al-Muqaddasī se situaría más bien en una tendencia intermedia o mediadora de un islam ecléctico (Miquel, 2001, pp. 279-280 y FrancoSánchez, 2018, pp. 127-128).

\section{A MODO DE CONCLUSIÓN}

A lo largo de estas líneas se ha pretendido mostrar cuáles son los puntos de interés que al-Muqaddasī transmite sobre el Occidente islámico y cómo concede tanta importancia a la geografía física, productiva y administrativa del territorio como al elemento humano que lo habitaba, aportando datos inestimables para los especialistas o interesados. Y todo ello, aprovechando la herencia recibida, apoyándose en fuentes e informantes, y sometiendo la información a una sistematización en la selección de los datos y un riguroso orden en la presentación de los mismos: la tipología administrativa, las rutas y distancias entre las ciudades, su morfología, sus recursos hídricos, sus cultivos, los habitantes y sus particularidades, y otros tantos aspectos que no he abordado en estas páginas para no alargarlas excesivamente. El mismo modelo y los mismos planteamientos que siguió al abordar otros territorios de la mamlaka los aplicó al Occidente islámico, como no podía ser de otra forma. Obviamente existen diferencias específicas en el tratamiento de las distintas provincias. Por ejemplo, he podido comprobar en el capítulo dedicado a al-Šām (Siria-Palestina), cómo su relato sobre los grupos e individuos es menos detallista que al hablar del Mágreb. También el estilo empleado adolece de una falta de objetividad, lo cual podría explicarse tal vez por los lazos afectivos con su tierra. Pero ello no resta valor alguno a su concepción geográfica, como señaló oportunamente A. Miquel: "Avec son Ahsan al-taqāsìm fi ma'rifat al-aqālīm [...] la géographie humaine du monde musulman trouve définitivement son sujet, son vocabulaire et sa méthode» (2001, p. 24).

\section{REFERENCIAS BIBLIOGRÁFICAS}

Ashtor, E. (1991). Makāyil. En C. E. Bosworth, E. Van Donzel, B. Lewis y Ch. Pellat, The Encyclopaedia of Islam² (volumen 6, pp. 117a-121a). Leiden: Brill. 
Bardenstein, C. (2002). Reconfiguring Food, Memory, and Gender in the Cookbook-Memoirs of Middle Eastern Exiles. Signs: Journal of Women in Culture and Society, 28(1), pp. 353-387. https://doi.org/10.1086/341011.

Bosworth, C. E. (1993). Mișr. En C. E. Bosworth, E. Van Donzel, B. Lewis, W. P. Heinrichs y Ch. Pellat, The Encyclopaedia of Islam ${ }^{2}$ (vol. 7, p. 146). Leiden-New York: Brill.

Cardarelli, F. (2003). Encyclopaedia of Scientific Units, Weights and Measures (1.. ed.). Springer-Verlag London. https://doi.org/10.1007/978-1-44710003-4.

Dozy, R. (1927). Aupplément aux Dictionaires Arabes. Leiden: Brill

Dozy, R. (1845). Dictionnaire détaillé des noms de vêtements chez les arabes. Amsterdam: Jean Müller.

Dozy, R. (1927). Supplément aux Dictionaires Arabes. Leiden: Brill.

De Felipe, H. (2018). The Butr and North African Ibāḍism: Praise and Criticism of the Berbers. En C. Aillet (ed.), L'ibadisme dans les sociétés islamiques médiévales (pp. 88-110). De Gruyter. https://doi. org/10.1515/9783110584394-009.

Franco-Sánchez, F. (2006). El occidente musulmán en los mapas del Mediterráneo de la «escuela de al-Balji». En A. I. Planet \& F. Ramos (Eds.), Relaciones hispano-marroquíes : una vecindad en construcción (pp. 38-53). Madrid: Ediciones del Oriente y del Mediterráneo. https:// doi.org/10.12795/PH.2017.i31.11.

Franco Sánchez, F. (2017) al-Masālik wa-I-Mamālik: precisiones acerca del título de estas obras de la literatura geográfica árabe medieval y conclusiones acerca de su origen y estructura. Philologia Hispalensis 31(2), pp. 37-66. https://doi.org/10.25145/j.cemyr.2018.26.05.

Franco-Sánchez, F. (2018). Al-Masālik wa-I-Mamālik (II). Construyendo una nueva imagen del mundo: Ruteros, geografía y cartografía al servicio de la causa šî'î. Cuadernos del CEMYR, 26, pp. 111-170. https://doi. org/10.25145/j.cemyr.2018.26.05. 
García San Juan, A. (2006). La caracterización de al-Andalus en los textos geográficos árabes orientales (siglos IX-XV). Norba. Revista de Historia, 19, pp. 43-59.

Huisman, A. J. W. (1986). Abū Qalamūn. En H. A. R. Gibb, J. H. Kramers, E. Lévi-Provençal y J. Schacht, The Encyclopaedia of Islam (Vol. 1, pp. 131). Leiden: E. J. Brill.

Lane, E. W. (Ed.). (1984) Arabic-English Lexicon (Vols. 1). Cambridge-England: The islamic texts society.

Manzano Rodríguez, M. A. (2017). El Magreb desde Oriente. Un acercamiento al Libro de los países de Ahmad al-Ya'qūbī. En F. Roldán y A. Contreras (Ed.), Paisajes, Espacios y Objetos de Devoción en el Islam (pp. 141-160). Sevilla: Universidad de Sevilla.

Miquel, A. (1963). Introduction. En al-Muqaddasi, Ahsan at-taqāsīm fi ma'rifat al-aqālīm = La meilleure répartition pour la conaissance des provinces / Al-Muqaddasī (pp. xxii - xxxviii). Damas: Institut Français de Damas.

Miquel, A. (1993). Al-Muḳaddasi. En C. E. Bosworth, E. Van Donzel, B. Lewis, W. P. Heinrichs y Ch. Pellat, The Encyclopaedia of Islam² (vol. 7, pp. 492493). Leiden-New York: Brill.

Miquel, A. (2001). Muqaddasī et son oeuvre : l'apogée des masālik wa almamālik. En La géographie humaine du monde musulman jusqu'au milieu du 11e siècle. Tome 1. Paris: Éditions de l'École des hautes études en sciences sociales. https://doi.org/10.4000/books.editionsehess.537.

Al-Muqaddasī, Šams al-Dīn Muḥammad b. Aḥmad. (1906). Iqlīm al-Magrib. En M. J. De Goeje (Ed.), Kitāb ahsan at-taqāsīm fi ma'rifat al-aqālīm (pp. 215-248). Leiden: Brill.

Pellat, Ch. (1950). Description de l'Occident Musulman au IV e =X e siècle. Alger: Editions Carbonel.

Serrano-Niza, D. (2005). Glosario árabe español de indumentaria según el Kitab al-Mujassas de Ibn Sidah. Madrid: CSIC. 
Tixier du Mesnil, E. (2014). Géographes d'Al-Andalus. De I'Inventaire d'un territoire à la construction d'une mémoire. Paris : Publications de la Sorbonne. https://doi.org/10.4000/books.psorbonne.36627. 